\title{
Thalassaemia major and the heart
}

\section{J. Malcolm Walker}

\section{University College and the Heart Hospitals, London, UK, Hatter Cardiovascular Institute, UCLH, London, UK}

\section{Introduction}

Disorders of haemoglobin synthesis are the commonest monogenetic disorders worldwide. When first described, thalassaemia was universally fatal in childhood, but after the adoption of regular blood transfusion survival until early teenage and adulthood was to be expected. At that stage in the life of these affected individuals organ failure followed, due to accumulated iron, for which the human has no excretory capacity. Principal amongst the tissues affected by iron overload is the heart and even to the present day, heart disease accounts for the overwhelming majority of premature deaths in this population. Managing transfusion derived iron overload was the next hurdle for clinicians and the families of the patients. For nearly four decades the only available treatment was the demanding regime of parenteral chelation therapy, required on a daily basis, to achieve growth, development and survival with limited or no organ damage. Despite the adoption of these treatment strategies the outlook for thalassaemia patients remained poor, with a $30 \%$ to $40 \%$ mortality occurring between late teenage and 30 years of age, even in well organised health care systems, such as in the UK, where regular transfusion and desferioxamine treatment were readily available. This dreadful early mortality, largely as a consequence of myocardial iron overload, $(1,2)$ is now improving so that in the UK and other developed nations, heart failure in thalassaemic patients has become uncommon and premature death a much rarer tragedy. This editorial reviews, from a personal viewpoint of a cardiologist involved in the care of these patients for the last 20 years, the progress in the management of the cardiovascular complications of thalassaemia major (TM), which has followed better techniques of identifying those thalassaemic individuals at greatest risk, improved chelation strategies making best use of the three

\section{Correspondence: J. Malcolm Walker}

A full version of this article, including a complete list of references will be published in Heart and will be available for viewing at "Heart.BMJ.com"

(C) Copyright J. Malcolm Walker, 2013

Licensee PAGEPress, Italy

Thalassemia Reports 2013; 3(s1):e8

doi:10.4081/thal.2013.s1.e8

This article is distributed under the terms of the Creative Commons Attribution Noncommercial License (by-nc 3.0) which permits any noncommercial use, distribution, and reproduction in any medium, provided the original author(s) and source are credited.

Parts of this work were presented at the

"3rd Pan-European Conference on Haemoglobinopathies and Rare Anaemias", Limassol (Cyprus), 24-26 October 2012. chelating agents that are now available and improved co-ordinated holistic treatment strategies, derived from a better understanding of this complicated disease state.

\section{The thalassaemias}

The first clinical descriptions of thalassaemia as a new disease entity were published in 1925 independently by Cooley in the United States and by Rietti, Greppi and Michelli in Italy. (3) The term thalassaemia was coined by Whipple in 1932 after performing the first autopsies in thalassaemic patients. Whipple wished to link the geographical origins of the patients he examined, the Mediterranean, with the blood disorder. This name was finally shortened to thalassaemia, a term that has persisted to this day. Over many decades, the underlying genetic abnormalities resulting in thalassaemia have been identified. (3)

Although the clinical manifestations of iron overload do not usually appear until the second decade of life, evidence from liver biopsies indicate that the damaging effects of iron accumulate much earlier than this. After approximately one year of transfusions, iron begins to be deposited in parenchymal tissues and may cause toxicity. (4) Where the heart is concerned the data support the impression that significant myocardial iron overload is seen after the age of $10 \mathrm{yr}$, (5) but sporadic reports exist of patients as young as $7 \mathrm{yr}$ having iron in the heart. (6)

\section{Iron toxicity}

Iron is a necessary constituent for cellular function, but it is rarely found unbound due to its highly reactive nature and ability to generate or catalyse the formation of toxic free radicals via the rapid Fenton reaction. (7) Iron is transported bound to the plasma protein transferrin and is taken up by cells via specific cell surface receptors. The regulation of iron metabolism is complex and incompletely understood. (8) In the presence of excess iron the carrying capacity of transferrin is exceeded and free non-transferrin bound iron(NTBI) is found in plasma. NTBI is taken up rapidly by myocytes, liver and other tissues. Uptake of iron into myocytes is complex and incompletely described, although the divalent metal transporter 1 (DMT1) and L-type calcium channels appear to be involved. $(9,10)$ The uptake of iron in heart cells may be influenced by other genetic factors, one such being glutathione S-transferase-M1(GSTM1) gene deletion, which has been associated with increased myocardial iron content. $(11,12)$

Iron once within the cell is bound to ferritin and transported to lysosomes for degradation and long-term storage. (13) If storage capacity is exceeded, free intracellular iron is able to be highly reactive (7) and cause multiple toxic cellular effects, including, impaired Na-K-ATPase activity, increased lysosomal fragility and impaired mitochondrial respiratory chain activity $(14,15,16)$ and the potential to worsen any 
ischaemia induced reperfusion injury. $(17,18)$ The eventual consequence is heart failure. (19)

The relatively mild degree of fibrosis in most autopsy studies suggests that even when advanced, the cardiomyopathy has the potential to be reversible. $(20,21,22)$ Thus the accumulation of iron within myocytes is a problem of storage, only when this capacity is exceeded, or the cell subjected to stress do the harmful effects of iron become manifest, raising the possibility that removal of excess iron deposits has the potential to restore the cell to normality, an observation made clinically on numerous occasions. $(23,24,25)$

\section{Clinical cardiovascular manifestations of thalassaemia}

The clinical presentation of thalassaemia varies greatly between individuals and at different ages. Infancy and childhood are dominated by the effects of anaemia a high cardiac output state and secondary spleen enlargement, but, as the transfused child ages, skeletal and endocrine effects appear, to be followed much later by the combined effects of the anaemia, erythroid marrow expansion, and the increasing effects of iron overload. As a consequence of the widespread iron deposition in the body, serious clinical complications arise by the involvement of the heart, liver and endocrine glands. Although myocyte dysfunction due to iron overload is the single most important cause of cardiac complications in thalassaemia, previously there was a significant incidence of myocarditis (4\% of a sample population), (26) although both conditions are much less common now, presumably due to improved treatment. (27)

The baseline haemodynamic state associated with thalassaemia affects the clinical assessment of patients and can complicate the diagnosis of ventricular dysfunction. Knowledge of these characteristics is important and informs the appropriate use of standard treatments of ventricular failure.

Despite regular transfusion, patients with thalassemia major are maintained with a mild chronic anemia (characteristically averaging $10 \mathrm{~g} / \mathrm{dl}$ ) and have a raised cardiac output. $(28,29)$ Additionally, there are physiological adaptations to this state, including increased left ventricular dimensions, when compared to age matched peer groups. (29) Systolic blood pressures are lower due to a reduced peripheral vascular resistance. (30) This hyperdynamic circulation is also evident in the higher ranges of ejection fraction seen in TM without iron overload, (29) (lower limit EF in this population is $>63 \%$ EF. $(31,32)$ Endothelial function is adversely affected by iron overload, with worsening in parameters of flow-mediated dilatation, which improve towards normal with iron chelation therapy. (33) Iron overload appears to accelerate age-related increases in vascular stiffness (34) and aortic and peripheral vascular compliance worsens with iron overload and with age. (35) These complex vascular effects have the potential to influence cardiac function and adaptation to stress. (36)

Cardiac iron overload is therefore rarely found in isolation, but is part of complex multisystem disease, even in a monogenetic disorder such as thalassaemia.

\section{Iron overload and the heart}

\section{Heart failure}

Once clinical evidence of cardiac failure is apparent in iron overloaded hearts the prognosis is poor, with mean survivals in the region of 3 months in historical reports (37) and remaining poor in more recent reports, where longer-term survival after heart failure in adult patients (ages $24 \pm 5$ years) was only $48 \%$. (38) Our own experience is that the acute mortality of overt severe cardiac failure is high, approximating $50 \%$, but, if intensive chelation is undertaken successfully, subsequent survival is good with normalisation of ventricular function to be expected, although clearance of cardiac iron lags behind improvements in systolic function, (23) with a high risk of relapse occurring if intensive chelation therapy is prematurely discontinued. (39) The clinical imperative is therefore to identify iron-overloaded hearts early, before severe myocyte failure occurs.

\section{Identifying thalassaemia patients at risk of heart failure}

In the past this was difficult. The non-specific nature of symptoms attributable to myocardial dysfunction reduces their reliability as discriminators between high and low risk patients. The chronic anaemia alone may account for much exercise limitation, although many patients with thalassaemia will be able to detect a progressive deterioration across time, which cannot be accounted for by their haemoglobin levels. The atrisk thalassaemic population could be found amongst the individuals, aged from teenage to early twenties, often with a history of difficulty with compliance to the DFO infusion regime. (40) Low risk individuals would tend to have long-term average ferritin levels under 1,500 with the absence of other organ involvement. (41) These patients were usually non-diabetic, with normal secondary sexual development, normal growth and endocrine function. Unfortunately, within any clinical service dealing with thalassaemia tragic exceptions occurred all too frequently. Patients who ostensibly were expected to be at low risk were subject to rapid decompensation. In the UK where the thalassaemia community is relatively small and close-knit, such unexpected deaths of young people had enormous effects on the morale and motivation of the survivors, further undermining compliance with a very demanding, often painful and socially debilitating form of treatment that DFO infusions represent.

Historically, the most accurate assessment of total iron burden relied upon quantitative iron measurement in liver biopsies. (42) However, the relationship between liver iron content and heart iron content is not constant. Finding a clear liver biopsy failed on occasion to identify some individuals, who were at great risk due to high heart iron content and the alternative scenario of low heart iron content with a high liver iron was also encountered. Myocardial biopsy had been used to risk stratify patients, (42) but its invasive nature and a concern over potential sampling errors precluded its routine use. (43)

The development of an MRI based non-invasive method to measure tissue iron accumulation (44) establishing the $\mathrm{T} 2 *$ parameter, transformed the ability to adequately risk stratify the thalassaemic patient population. Cardiac T2* has been shown from a study of autopsy hearts to have a predictable relationship to physical iron content. (45) Increasing iron content, as shown by low $\mathrm{T}^{*}$ is associated with increasingly impaired ventricular function. $(46,47)$ The $\mathrm{T} 2 *$ also responds to increased chelation treatment by showing a progressive rise towards normality associated with a dissociated, faster, improvement in ventricular function. $(23,33)$ A prospective follow-up of more than 600 UK patients revealed that a T2* $<6$ ms conferred a $47 \%$ chance of developing heart failure within one year and $98 \%$ of patients with diagnosed heart failure had a T2* $<10 \mathrm{~ms}$. (48) There was a demonstrable dose-response, where higher $\mathrm{T} 2 *$ values were associated with decreasing risks of heart failure.

Within the thalassaemia population there is a group (approximately 40\%) with normal LV function by conventional testing (EF), but severe iron loading, demonstrated by a low T2* $(<10 \mathrm{~ms})$. (47) These individuals pose a high risk of developing cardiac complications. These patients, before the advent of MR T2* measurements, went undetected and were not prescribed the intensified treatment regimes known to improve cardiac outcomes. 
As a result, some have postulated that recent improvements in life expectancy for thalassemia major patients in the UK and elsewhere, (2) can be explained by the increasing availability of cardiac MRI and earlier escalation of therapy. (49)

\section{Arrhythmia and heart conduction abnormalities}

Iron overloaded hearts are susceptible to arrhythmia, occurring in $50 \%$ of patients from historical series of TM patients not receiving chelation. (50) It is not surprising therefore that palpitations are a relatively frequent complaint, as they are in any general cardiology service. They occasionally are due to life-threatening ventricular tachycardia (VT) $(<1 \%)$, (48) but this is usually in grossly iron-overloaded hearts with established ventricular impairment. Atrial fibrillation is fairly common with a $12 \%$ incidence within a year in the prospective UK study (48) but a much lower incidence reported for a large cohort in Italy. (31) AF was previously associated with the risk of impending cardiac failure and was greatly feared by TM patients, who were aware of it as a harbinger of impending heart failure and likely mortality.

The demographic characteristic of AF appears to be changing in our clinics. A recent survey revealed a $9 \%$ prevalence of AF and $34 \%$ incidence of documented AF or paroxysmal AF within the last 12 months amongst a cohort of TM patients of mean age 38 years, with good LV function and normal T2*values (unpublished observations, M Walker). In this ageing group, none of whom had significant current myocardial iron loading, the AF appeared to represent the very late manifestation of an historical cardiac iron overload.

The problem facing the clinician is differentiating between sinister arrhythmias and the more common benign palpitations experienced by a young population, often anxious, who have first-hand experience of the outcomes of some of their less fortunate peers. Having a quantitative estimate of cardiac iron content, by $\mathrm{T} 2 *$, and current knowledge of ventricular function is essential in making this distinction.

Conduction disturbance and complete heart block (CHB) occurred in $40 \%$ of 16 to $20 \mathrm{yr}$ old TM patients who did not receive any chelation in an early series. (50) In current practice heart block is rare. When encountered, CHB may respond to intensive chelation therapy and removal of myocardial iron, but the rate of progress is so slow that in the intervening period there will be a need to consider the use of a permanent pacemaker. In view of the essential nature of MR scanning in the continued assessment of TM patients, any devices used must be MR compatible.

\section{Treatment of myocardial iron overload}

The mainstay of treatment for iron overload remains the administration of desferoxamine (DFO), using prolonged subcutaneous or intravenous infusions. The introduction of DFO in the $1960 \mathrm{~s}$ had a profound effect on mortality in TM. Although not specifically documented this was undoubtedly dominated by a reduction in cardiac mortality.

Patients at high risk of complications, or those with established evidence of cardiac dysfunction need an intensive regime of treatment, which usually means constant 24 hour infusions for 7 days per week. These can be achieved using sub-cutaneous infusions, but more often, particularly in the more severely ill patients, constant intra-venous infusions are more effective. Chronic indwelling venous catheters or sub-cutaneous ports (Port-a-Cath) are preferable, since the chronic intra-venous treatment may have to be continued for years to achieve effective iron removal from the tissues. Focusing the most intensive regimes on those at greatest risk is an important clinical aim. To this end, aggressive treatment regimes can easily be justified in patients with established myocardial dysfunction or symptoms. With the advent of MRI T2* encouraging such treatment in patients with high heart iron content, before there is any evidence ventricular impairment is appropriate.

Deferoxamine is not only difficult to use, but also remains very expensive and a proportion of patients develop allergies. An oral iron chelator, deferiprone (Ferriprox, ApoPharma; L1) has been available for some years. (51) Initially heralded as a great advance, it subsequently attracted adverse publicity from some quarters. (52) This negative data has been contrasted with positive results in several other studies, both retrospective $(53,54)$ and prospective. $(33,47)$ Deferiprone may have an advantage over DFO in its ability to enter the cell (55) and remove accumulated iron from the cytosol and probably from mitochondria. Combining treatment with DFO and deferiprone may have a particular advantage. The most recent addition to the chelation therapeutic field is another oral agent desferasirox,(Exjade; ICL370) (DFX), which has been licensed for use by the FDA and the European regulatory authorities and its clinical role is becoming more clearly defined. $(56,57)$

\section{Specific cardiological care}

The essence of treatment of cardiac disease should be aggressive chelation therapy to rapidly counteract iron toxicity and progressively remove excessive iron deposits. $(39,58)$ In recent years, there has been a consistent trend to treat patients with thalassaemia who have mild ventricular dysfunction with agents known to improve myocardial function in other forms of cardiomyopathy, such as ACE inhibitors, angiotensin receptor blockers and beta-blockers. These drugs are established forms of treatment in cardiomyopathy, and while their extension to heart failure in thalassaemia remains conjectural, it is widely applied in clinical practice. Low blood pressure limits the use of these drugs in the TM population, as it does the use of beta-blockers for the treatment of symptomatic arrhythmia.

A special caution needs to be raised for the use of loop diuretics in the decompensated TM patient. Whilst symptomatic benefit may follow their use for pulmonary congestion or signs of right-sided heart failure, the tendency for thalassaemia patients to have low blood pressure plus a restrictive physiology, can precipitate a sudden fall in cardiac output and induce pre-renal failure.

\section{Summary}

For most cardiologists, thalassaemia major and the cardiomyopathy of iron overload remain infrequently observed clinical curiosities. Worldwide these are important problems, where, unusually, there exists a preventable form of cardiomyopathy, which, poorly managed, has the capacity to radically shorten lives and be the cause of distressing morbidity. In many countries, mostly in the developed nations, there has been a dramatic reduction in the death rate associated with the cardiovascular consequences of the condition. These improvements have arisen from clinical research and the more careful application of existing technologies and treatments to the individuals at highest risk, rather than to radical new discoveries.

TM also affords the opportunity to understand myocardial adaptive processes. This is a unique group of patients with a single cause for cardiac failure, which develops with an incidence of 3-5\% per year even in those well-chelated adults with thalassaemia. Many of the mutations causing -thalassaemia have been identified, and some of the reasons behind the very variable phenotypic expression of this monogenetic disorder are being unraveled. More uncertainties exist than answers, serving as a caution to the optimistic view that knowing the gene defect can 
easily predict phenotype and then translate into clinical practice. Managing these patients optimally will still require careful clinical observation, measurement and well-planned trials of new therapies.

\section{References}

1. Borgna-Pignatti, C., Rugolotto, S., De, S. P., Zhao, H., Cappellini, M. D., Del Vecchio, G. C. et al. (2004). Survival and complications in patients with thalassemia major treated with transfusion and deferoxamine. Haematologica, 89, 1187-1193.

2. Telfer, P., Coen, P. G., Christou, S., Hadjigavriel, M., Kolnakou, A., Pangalou, E. et al. (2006). Survival of medically treated thalassemia patients in Cyprus. Trends and risk factors over the period 1980-2004. Haematologica, 91, 1187-1192.

3. Weatherall, D. J. (2004). Thalassaemia: the long road from bedside to genome. Nat.Rev.Genet., 5, 625-631.

4. Risdon, R. A., Flynn, D. M., \& Barry, M. (1973). The relation between liver iron concentration and liver damage in transfusional iron overload in thalassaemia and the effect of chelation therapy. Gut, 14,421 .

5. Wood, J. C. (2008). Cardiac iron across different transfusiondependent diseases. Blood Rev., 22 Suppl 2, S14-S21.

6. Fernandes, J. L., Fabron, A., Jr., \& Verissimo, M. (2009). Early cardiac iron overload in children with transfusion-dependent anemias. Haematologica, 94, 1776-1777.

7. Arosio, P. \& Levi, S. (2010). Cytosolic and mitochondrial ferritins in the regulation of cellular iron homeostasis and oxidative damage. Biochim.Biophys.Acta, 1800, 783-792.

8. Anderson, G. J., Darshan, D., Wilkins, S. J., \& Frazer, D. M. (2007). Regulation of systemic iron homeostasis: how the body responds to changes in iron demand. Biometals, 20, 665-674.

9. Ludwiczek, S., Theurl, I., Muckenthaler, M. U., Jakab, M., Mair, S. M., Theurl, M. et al. (2007). Ca2+ channel blockers reverse iron overload by a new mechanism via divalent metal transporter-1. Nat.Med., 13, 448-454.

10. Oudit, G. Y., Sun, H., Trivieri, M. G., Koch, S. E., Dawood, F., Ackerley, C. et al. (2003). L-type $\mathrm{Ca} 2+$ channels provide a major pathway for iron entry into cardiomyocytes in iron-overload cardiomyopathy. Nat.Med., 9, 1187-1194.

11. Origa, R., Satta, S., Matta, G., \& Galanello, R. (2008). Glutathione S-transferase gene polymorphism and cardiac iron overload in thalassaemia major. Br.J.Haematol., 142, 143-145.

12. Wu, K. H., Chang, J. G., Ho, Y. J., Wu, S. F., \& Peng, C. T. (2006). Glutathione S-transferase M1 gene polymorphisms are associated with cardiac iron deposition in patients with beta-thalassemia major. Hemoglobin, 30, 251-256.

13. Wood, J. C., Origa, R., Agus, A., Matta, G., Coates, T. D., \& Galanello, R. (2008). Onset of cardiac iron loading in pediatric patients with thalassemia major. Haematologica, 93, 917-920.

14. Link, G. \& Hershko, C. (1993). Rat heart cells in culture: a model of iron toxicity and chelation. J Lab Clin.Med., 122, 14-15.

15. Link, G., Pinson, A., \& Hershko, C. (1994). Ability of the orally effective iron chelators dimethyl- and diethyl-hydroxypyrid-4-one and of deferoxamine to restore sarcolemmal thiolic enzyme activity in iron-loaded heart cells. Blood, 83, 2692-2697.

16. Link, G., Tirosh, R., Pinson, A., \& Hershko, C. (1996). Role of iron in the potentiation of anthracycline cardiotoxicity: identification of heart cell mitochondria as a major site of iron-anthracycline interaction. J Lab Clin.Med., 127, 272-278.

17. Horwitz, L. D. \& Rosenthal, E. A. (1999). Iron-mediated cardiovascular injury. Vasc.Med., 4, 93-99.

18. Liu, P. \& Olivieri, N. (1994). Iron overload cardiomyopathies: new insights into an old disease. Cardiovasc.Drugs Ther., 8, 101-110.

19. Hershko, C., Link, G., \& Cabantchik, I. (1998). Pathophysiology of iron overload. Ann.N.Y.Acad.Sci., 850, 191-201.

20. Buja, L. M. \& Roberts, W. C. (1971). Iron in the heart. Etiology and clinical significance. Am.J.Med., 51, 209-221.

21. Kirk, P., Carpenter, J. P., Tanner, M. A., \& Pennell, D. J. (2011). Low prevalence of fibrosis in thalassemia major assessed by late gadolinium enhancement cardiovascular magnetic resonance. J Cardiovasc.Magn Reson., 13, 8.

22. Kirk, P., Sheppard, M. N., Carpenter, J. P., Anderson, L. J., He, T., De Noronha, S. et al. (2012). Fibrosis in cardiac siderosis: update on historical perspectives. Haematologica, 97, 166.

23. Anderson, L. J., Westwood, M. A., Holden, S., Davis, B., Prescott, E., Wonke, B. et al. (2004). Myocardial iron clearance during reversal of siderotic cardiomyopathy with intravenous desferrioxamine: a prospective study using $\mathrm{T} 2 *$ cardiovascular magnetic resonance. Br.J.Haematol., 127, 348-355.

24. Miskin, H., Yaniv, I., Berant, M., Hershko, C., \& Tamary, H. (2003). Reversal of cardiac complications in thalassemia major by longterm intermittent daily intensive iron chelation. Eur.J Haematol., 70, 398-403.

25. Politi, A., Sticca, M., \& Galli, M. (1995). Reversal of haemochromatotic cardiomyopathy in beta thalassaemia by chelation therapy. Br.Heart J, 73, 486-487.

26. Kremastinos, D. T., Tiniakos, G., Theodorakis, G. N., Katritsis, D. G., \& Toutouzas, P. K. (1995). Myocarditis in beta-thalassemia major. A cause of heart failure. Circulation, 91, 66-71.

27. Aessopos, A., Berdoukas, V., \& Tsironi, M. (2008). The heart in transfusion dependent homozygous thalassaemia today-prediction, prevention and management. Eur.J Haematol., 80, 93-106.

28. Aessopos, A., Farmakis, D., Hatziliami, A., Fragodimitri, C., Karabatsos, F., Joussef, J. et al. (2004). Cardiac status in well-treated patients with thalassemia major. Eur.J.Haematol., 73, 359-366.

29. Westwood, M. A., Anderson, L. J., Maceira, A. M., Shah, F. T., Prescott, E., Porter, J. B. et al. (2007). Normalized left ventricular volumes and function in thalassemia major patients with normal myocardial iron. J.Magn Reson.Imaging, 25, 1147-1151.

30. Veglio, F., Melchio, R., Rabbia, F., Molino, P., Genova, G. C., Martini, G. et al. (1998). Blood pressure and heart rate in young thalassemia major patients. Am.J Hypertens., 11, 539-547.

31. Marsella, M., Borgna-Pignatti, C., Meloni, A., Caldarelli, V., Dell'Amico, M. C., Spasiano, A. et al. (2011). Cardiac iron and cardiac disease in males and females with transfusion-dependent thalassemia major: a T2* magnetic resonance imaging study. Haematologica, 96, 515-520.

32. Pennell, D. J., Carpenter, J. P., Roughton, M., \& Cabantchik, Z. (2011). On improvement in ejection fraction with iron chelation in thalassemia major and the risk of future heart failure. J Cardiovasc.Magn Reson., 13, 45.

33. Tanner, M. A., Galanello, R., Dessi, C., Smith, G. C., Westwood, M. A., Agus, A. et al. (2007). A randomized, placebo-controlled, doubleblind trial of the effect of combined therapy with deferoxamine and deferiprone on myocardial iron in thalassemia major using cardiovascular magnetic resonance. Circulation, 115, 1876-1884.

34. Stakos, D. A., Tavridou, A., Margaritis, D., Tziakas, D. N., Kotsianidis, I., Chalikias, G. K. et al. (2009). Oxidised low-density lipoprotein and arterial function in beta-thalassemia major. Eur.J Haematol., 82, 477-483.

35. Cheung, Y. F., Chan, G. C., \& Ha, S. Y. (2002). Arterial stiffness and endothelial function in patients with beta-thalassemia major. Circulation, 106, 2561-2566.

36. Bosi, G., Crepaz, R., Gamberini, M. R., Fortini, M., Scarcia, S., Bonsante, E. et al. (2003). Left ventricular remodelling, and systolic and diastolic function in young adults with beta thalassaemia 
major: a Doppler echocardiographic assessment and correlation with haematological data. Heart, 89, 762-766.

37. ENGLE, M. A., ERLANDSON, M., \& SMITH, C. H. (1964). LATE CARDIAC COMPLICATIONS OF CHRONIC, SEVERE, REFRACTORY ANEMIA WITH HEMOCHROMATOSIS. Circulation, 30, 698-705.

38. Kremastinos, D. T., Tsetsos, G. A., Tsiapras, D. P., Karavolias, G. K., Ladis, V. A., \& Kattamis, C. A. (2001). Heart failure in beta thalassemia: a 5-year follow-up study. Am.J Med., 111, 349-354.

39. Davis, B. A. \& Porter, J. B. (2000). Long-term outcome of continuous 24-hour deferoxamine infusion via indwelling intravenous catheters in high-risk beta-thalassemia. Blood, 95, 1229-1236.

40. Aldouri, M. A., Wonke, B., Hoffbrand, A. V., Flynn, D. M., Ward, S. E., Agnew, J. E. et al. (1990). High incidence of cardiomyopathy in beta-thalassaemia patients receiving regular transfusion and iron chelation: reversal by intensified chelation. Acta Haematol., 84, 113-117.

41. Telfer, P. T., Prestcott, E., Holden, S., Walker, M., Hoffbrand, A. V., \& Wonke, B. (2000). Hepatic iron concentration combined with longterm monitoring of serum ferritin to predict complications of iron overload in thalassaemia major. Br.J.Haematol., 110, 971-977.

42. Borgna-Pignatti, C. \& Castriota-Scanderbeg, A. (1991). Methods for evaluating iron stores and efficacy of chelation in transfusional hemosiderosis. Haematologica, 76, 409-413.

43. Fitchett, D. H., Coltart, D. J., Littler, W. A., Leyland, M. J., Trueman, T., Gozzard, D. I. et al. (1980). Cardiac involvement in secondary haemochromatosis: a catheter biopsy study and analysis of myocardium. Cardiovasc.Res., 14, 719-724.

44. Anderson, L. J., Holden, S., Davis, B., Prescott, E., Charrier, C. C., Bunce, N. H. et al. (2001). Cardiovascular T2-star (T2*) magnetic resonance for the early diagnosis of myocardial iron overload. Eur.Heart J., 22, 2171-2179.

45. Carpenter, J. P., He, T., Kirk, P., Roughton, M., Anderson, L. J., de Noronha, S. V. et al. (2011). On T2* magnetic resonance and cardiac iron. Circulation, 123, 1519-1528.

46. Patton, N., Brown, G., Leung, M., Bavishi, K., Taylor, J., Lloyd, J. et al. (2010). Observational study of iron overload as assessed by magnetic resonance imaging in an adult population of transfusiondependent patients with beta thalassaemia: significant association between low cardiac T2* $<10 \mathrm{~ms}$ and cardiac events. Intern.Med.J., 40, 419-426.

47. Tanner, M. A., Galanello, R., Dessi, C., Westwood, M. A., Smith, G.
C., Nair, S. V. et al. (2006). Myocardial iron loading in patients with thalassemia major on deferoxamine chelation. J.Cardiovasc.Magn Reson., 8, 543-547.

48. Kirk, P., Roughton, M., Porter, J. B., Walker, J. M., Tanner, M. A., Patel, J. et al. (2009). Cardiac T2* magnetic resonance for prediction of cardiac complications in thalassemia major. Circulation, 120, 1961-1968.

49. Modell, B., Khan, M., Darlison, M., Westwood, M. A., Ingram, D., \& Pennell, D. J. (2008). Improved survival of thalassaemia major in the UK and relation to $\mathrm{T} 2 *$ cardiovascular magnetic resonance. J Cardiovasc.Magn Reson., 10, 42.

50. Ehlers, K. H., Levin, A. R., Markenson, A. L., Marcus, J. R., Klein, A. A., Hilgartner, M. W. et al. (1980). Longitudinal study of cardiac function in thalassemia major. Ann.N.Y.Acad.Sci., 344, 397-404.

51. al-Refaie, F. N., Hershko, C., Hoffbrand, A. V., Kosaryan, M., Olivieri, N. F., Tondury, P. et al. (1995). Results of long-term deferiprone (L1) therapy: a report by the International Study Group on Oral Iron Chelators. Br.J.Haematol., 91, 224-229.

52. Olivieri, N. F. \& Brittenham, G. M. (1998). Long-term trials of deferiprone in Cooley's anemia. Ann.N.Y.Acad.Sci., 850, 217-222.

53. Anderson, L. J., Wonke, B., Prescott, E., Holden, S., Walker, J. M., \& Pennell, D. J. (2002). Comparison of effects of oral deferiprone and subcutaneous desferrioxamine on myocardial iron concentrations and ventricular function in beta-thalassaemia. Lancet, 360, 516520.

54. Borgna-Pignatti, C., Cappellini, M. D., De, S. P., Del Vecchio, G. C., Forni, G. L., Gamberini, M. R. et al. (2006). Cardiac morbidity and mortality in deferoxamine- or deferiprone-treated patients with thalassemia major. Blood, 107, 3733-3737.

55. Shalev, 0., Repka, T., Goldfarb, A., Grinberg, L., Abrahamov, A., Olivieri, N. F. et al. (1995). Deferiprone (L1) chelates pathologic iron deposits from membranes of intact thalassemic and sickle red blood cells both in vitro and in vivo. Blood, 86, 2008-2013.

56. Berdoukas, V., Farmaki, K., Wood, J. C., \& Coates, T. (2011). Iron chelation in thalassemia: time to reconsider our comfort zones. Expert.Rev.Hematol., 4, 17-26.

57. Berdoukas, V. \& Wood, J. (2011). In search of the optimal iron chelation therapy for patients with thalassemia major. Haematologica, 96, 5-8.

58. Davis, B. A. \& Porter, J. B. (2002). Results of long term iron chelation treatment with deferoxamine. Adv.Exp.Med Biol., 509, 91-125.

\section{Oral presentation}

Oral presentation is available online 